\title{
High gain signal averaged electrocardiogram combined with 24 hour monitoring in patients early after myocardial infarction for bedside prediction of arrhythmic events
}

\author{
T CRIPPS, * E D BENNETT, $\dagger$ A J CAMM, * D E WARD * \\ From the Departments of ${ }^{\star}$ Cardiological Sciences and †Medicine I, St George's Hospital Medical School, \\ London
}

SUMMARY The value of the high gain, signal averaged electrocardiogram combined with 24 hour electrocardiographic monitoring in the prediction of arrhythmic events was assessed in 159 patients in the first week after myocardial infarction. Eleven patients $(7 \%)$ suffered arrhythmic events during a mean (SD) of 12 (6) months of follow up (range 2-22, median 13 months). The combination of high gain, signal averaged electrocardiography and 24 hour electrocardiographic monitoring was more accurate than either technique alone or than clinical information collected during admission in predicting these events. The combination identified a high risk group of 13 $(8 \%)$ patients, with an arrhythmic event rate of $62 \%$ and a low risk group with an event rate of $2 \%$.

The combination of high gain, signal averaged electrocardiography and 24 hour electrocardiographic monitoring in the first week after myocardial infarction provides a rapid, cheap, and non-invasive bedside method for the prediction of arrhythmias.

The assessment of prognosis after myocardial infarction is of potential value, both to those judged to be at low risk, who can be reassured and spared further investigation and treatment, and to those at high risk, upon whom diagnostic and therapeutic facilities can be focused. An assessment of any tendency to cardiac arrhythmias is especially important in patients after myocardial infarction since ventricular arrhythmias have been strongly implicated as an important cause of sudden death in this group. ${ }^{2}$ Recently it has been shown that areas of late myocardial depolarisation, which may be a basis for re-entry, can be detected at the body surface by a high gain signal averaged electrocardiogram. ${ }^{3}$

As with 24 hour electrocardiographic monitoring, however, the predictive accuracy of the signal averaged electrocardiogram is low, limiting its clinical usefulness. A combination of signal averaged

Requests for reprints to Dr T Cripps, Department of Cardiological Sciences, St George's Hospital Medical School, Cranmer Terrace, Tooting, London SW 17 ORE.

Accepted for publication 17 May 1988 electrocardiography and 24 hour electrocardiographic monitoring increased the accuracy of arrhythmia prediction. ${ }^{45}$ We have therefore carried out a prospective study of a population of consecutive patients with myocardial infarction to confirm and extend these observations. In this study we also considered the value of signal averaged electrocardiogram recordings obtained within the first 72 hours after infarction.

\section{Patients and methods}

All patients of $\leqslant 70$ admitted to the hospital between 1 May 1986 and 1 December 1987 as general medical emergencies having sustained a myocardial infarction within the previous 24 hours were seen within 48 hours of admission and considered for inclusion in the study, which was approved by the regional ethics committee. Myocardial infarction was diagnosed when two or more of the following features were present: (a) chest pain suggestive of myocardial ischaemia persisting for at least 20 minutes and unrelieved by glyceryl trinitrate; (b) sequential rise and fall in the plasma concentrations of aspartate 
transaminase, 2-hydroxybutyrate dehydrogenase, and/or creatine kinase with a peak concentration of at least twice the upper limit of the reference range for our laboratory; (c) development of new abnormal $Q$ waves, or persistent $S T / T$ changes suggestive of non- $Q$ wave myocardial infarction. Patients were excluded if they had non-cardiac disease likely to influence mortality, important non-ischaemic cardiac disease, a history of previous cardiac surgery or permanent pacemaker insertion, if they had atrial fibrillation or bundle branch block, if they refused or were unable to attend for follow up. Since this was a long term prognostic study, we also excluded patients who died or had operation within seven days after the onset of myocardial infarction, the usual time of hospital discharge. To ensure that the population studied would be representative of patients admitted to a general hospital with myocardial infarction we excluded patients transferred from other hospitals to the regional cardiothoracic unit. Those with previous infarction were included, as were those with both $Q$ and non- $Q$ wave infarction.

\section{CLINICAL ASSESSMENT}

TC obtained a history and carried out a physical examination in all cases as soon as possible after admission. The 12 lead electrocardiogram and chest radiograph were reviewed and the Killip class ${ }^{6}$ and Norris index ${ }^{7}$ were determined. Blood was sent for measurement of cardiac enzymes, and a 12 lead electrocardiogram was recorded on admission and on the morning of the first three days after admission. Patients were monitored on the intensive care unit for the first 24-48 hours or as clinical circumstances dictated and early arrhythmias were recorded by a central monitoring system. During admission patients were reviewed daily and the occurrence of in-hospital complications was noted.

\section{SIGNAL AVERAGED ELECTROCARDIOGRAM}

A high gain, signal averaged electrocardiogram was obtained during admission with a commercially available system (Model 101 electrocardiograph, Arrhythmia Research Technology, Oklahoma, USA). This system uses the method developed by Simson for the detection of late potentials and has been described in detail elsewhere. ${ }^{8}$ Briefly, after preparation of the skin with an alcohol swab and careful abrasion, pre-gelled electrodes were applied in the Frank orthogonal lead configuration and the surface electrocardiogram was amplified by a factor of 5000, digitised, filtered low-pass at $250 \mathrm{~Hz}$ and high-pass at $25 \mathrm{~Hz}$ (with bidirectional filters to eliminate ringing), and $200-500$ beats were averaged to achieve a noise level of $<1.0 \mu \mathrm{V}$. A vector magnitude display (the filtered QRS complex) was generated, and the late potentials were defined as the presence of one or more of: (a) filtered QRS duration (fQRSD) of $\geqslant 120 \mathrm{~ms}$; (b) duration of the filtered QRS complex after voltage falls below $40 \mu \mathrm{V}$ (LPD40) of $\geqslant 40 \mathrm{~ms}$, and (c) root mean square voltage during the last $40 \mathrm{~ms}$ of the filtered $\mathrm{QRS}$ complex (RMSV40) of $\leqslant 25 \mu \mathrm{V}$. The signal averaged electrocardiogram was obtained at the bedside within 5-10 minutes.

Reproducibility was assessed in 20 patients selected at random at one month after myocardial infarction. Consecutive recordings were made without any technical or environmental changes, both recordings being completed within 15 minutes. The noise level achieved in the two recordings was the same, to within $\pm 0.1 \mu \mathrm{V}$ in each subject. Changes in the signal averaged electrocardiographic variables were assessed in $\mathbf{5 8}$ patients who had an initial recording within 72 hours of the onset of symptoms and a second recording at the first outpatient follow up visit.

\section{HOUR MONITORING}

The electrocardiogram was monitored for 24 hours $>6$ days after myocardial infarction on a Tracker recorder (Reynolds Medical Ltd., Hertford, England). Leads CM5 and modified lead III were recorded. We used a semiautomated system to analyse the 24 hour electrocardiograms for arrhythmias (Pathfinder III system, Reynolds Medical Ltd., Hertford). The frequency of ventricular extrasystoles over the 24 hour period was calculated and the occurrence of multiform extrasystoles, couplets, and ventricular tachycardia (a run of three or more ventricular extrasystoles) was noted. In no case was the occurrence of asymptomatic arrhythmias on 24 hour monitoring considered to be an arrhythmic event.

\section{FOLLOW UP}

Patients were seen at $1,3,6$, and 12 months, or as clinical circumstances dictated. We telephoned the patient's general practitioner and relatives if a patient did not attend for a clinic appointment to find out whether the patient had died, and if so how. Sudden cardiac death was defined as witnessed sudden death in or out of hospital not preceded by chest pain. Sustained ventricular tachycardia was defined as documented ventricular tachycardia lasting for 30 seconds or associated with symptomatic hypotension. An arrhythmic event was defined as either sudden cardiac death or the occurrence of sustained ventricular tachycardia. In all cases the arrhythmic events occurred after completion of the signal averaged electrocardiogram and 24 hour tape. 


\section{Results}

\section{PATIENT POPULATION}

During the period of this study, May 1986 to December 1987, 232 patients under the age of 71 were admitted to the hospital as general medical emergencies with proven myocardial infarction and without other life threatening disease. After exclusion because of death (22) or cardiac surgery (4) within seven days of infarction, previous cardiac surgery (6), refusal or inability to attend follow up (9), bundle branch block (7), atrial fibrillation (2), technical problems with the 24 hour electrocardiogram (13), and administrative problems (10), 159 patients remained who had both signal averaged electrocardiography and 24 hour electrocardiography. The mean (SD) age of this group was 56 (9) years (range 28-70). Twenty per cent were female; there was a history of previous infarction in $14 \%$. $Q$ wave infarction was present in $67 \%$ and non- $Q$ wave infarction in $33 \%$. The Killip class on admission was I in $88 \%$, II in $8 \%$, III in $3 \%$, and IV in $1 \%$; the Norris index was $>10$ in $7 \%$.

HIGH GAIN, SIGNAL AVERAGED

\section{ELECTROCARDIOGRAPHY}

The initial signal averaged electrocardiogram recording was made (mean (SD)) 3(2) days (range 0-10, median 3) after infarction. A late potential, as defined above, was present in $38 / 159(24 \%)$ of patients. In the reproducibility study, the standard deviation of the differences between the first and second recordings was $4 \mathrm{~ms}$ for fQRSD, $2.9 \mathrm{~ms}$ for LPD40, and 6.1 $\mathrm{ms}$ for RMSV40. The range within which a single measurement could be reproduced (with $95 \%$ probability) on a second occasion was thus $\pm 8 \mathrm{~ms}$ for fQRSD, $\pm 6 \mathrm{~ms}$ for LDP40, and $\pm 12 \mu \mathrm{V}$ for RMSV40. Of those 58 patients in whom an initial recording was made $<\mathbf{7 2}$ hours after infarction and repeated at follow up, nine $(82 \%)$ of 11 patients had late potentials at both recordings, and five of these had arrhythmic events (one sudden cardiac death and four ventricular tachycardia). Of those 47 patients with an early initial recording without late potentials, only two (4\%) had them at follow up; neither of these patients had an arrhythmic event. All of these changes were outside the $95 \%$ confidence intervals. There was no significant change in the mean values of the signal averaged electrocardiogram variables between recordings obtained within the first 72 hours and at follow up.

\section{TWENTY FOUR HOUR ELECTROCARDIOGRAPHIC MONITORING}

Twenty four hour electrocardiograms were recorded $>6$ days after infarction in all patients. In 30 patients there were $>10$ ventricular extrasystoles per hour. Ventricular tachycardia (three or more consecutive beats) were recorded in 12 patients.

\section{FOLLOW UP}

No patient was lost to follow up. During follow up of (mean (SD)) 12(6) months (range 2-16) seven patients died, five of them in circumstances suggesting a primarily arrhythmic death, and six had documented sustained symptomatic ventricular tachycardia occurring more than 48 hours after myocardial infarction. Thus there were $11(7 \%)$ patients who had an arrhythmic event. Table 1 shows the sensitivity, specificity, and positive predictive value of the high gain signal averaged electrocardiogram and of 24 hour electrocardiographic monitoring in predicting these events. It is clear that on their own both 24 hour tape and signal averaged electrocardiogram were fairly sensitive in predicting arrhythmic events but had low positive predictive accuracy $(27 \%$ for 24 hour tape and $26 \%$ for late potentials). When both tests were positive the positive predictive accuracy for predicting arrhythmic events was, however, much higher $(62 \%)$ yet the sensitivity of the combination was retained $(73 \%)$. All but one of the patients with positive results in both tests but no arrhythmic events had undergone coronary artery bypass surgery, which may have influenced the outcome.

Table 1 also shows the value of the clinical findings

Table 1 Value (\%) of ambulatory monitoring and signal averaged electrocardiography in predicting risk of arrhythmic events

\begin{tabular}{|c|c|c|c|c|}
\hline & Sensitivity & Specificity & $P P A$ & Efficiency \\
\hline $\begin{array}{l}\text { Killip class } \geqslant \text { II } \\
\text { Norris index }>9 \\
\text { Signal averaged ECG }(\mathrm{LP}+\text { ) } \\
24 \text { hour tape (FVE } \geqslant 10 / \text { hour) } \\
\text { Both tape and Killip class } \geqslant \text { II } \\
\text { Both LP }+ \text { and Killip class } \geqslant \text { II } \\
\text { Both LP + and FVE } \geqslant 10 / \text { hour }\end{array}$ & $\begin{array}{l}6 / 11(55) \\
5 / 11(45) \\
10 / 11(91) \\
8 / 11(73) \\
4 / 11(36) \\
5 / 11(45) \\
8 / 11(73)\end{array}$ & $\begin{array}{l}135 / 148(91) \\
141 / 148(95) \\
120 / 148(81) \\
126 / 148(85) \\
144 / 148(97) \\
145 / 148(98) \\
143 / 148(97)\end{array}$ & $\begin{array}{l}6 / 19(32) \\
5 / 12(42) \\
10 / 38(26) \\
8 / 30(27) \\
4 / 8(50) \\
5 / 8(63) \\
8 / 13(62)\end{array}$ & $\begin{array}{l}141 / 159(89) \\
146 / 159(92) \\
130 / 159(82) \\
134 / 159(84) \\
148 / 159(93) \\
150 / 159(94) \\
151 / 159(97)\end{array}$ \\
\hline
\end{tabular}

PPA, positive predictive accuracy; LP+, late potentials present; FVE, frequency of ventricular extrasystoles. 
(a)

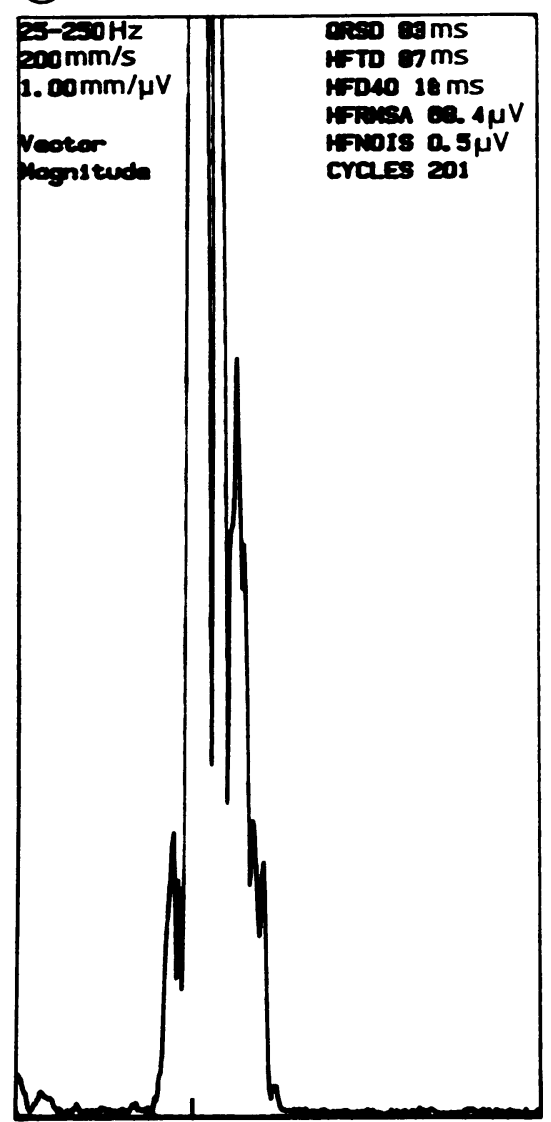

(b)

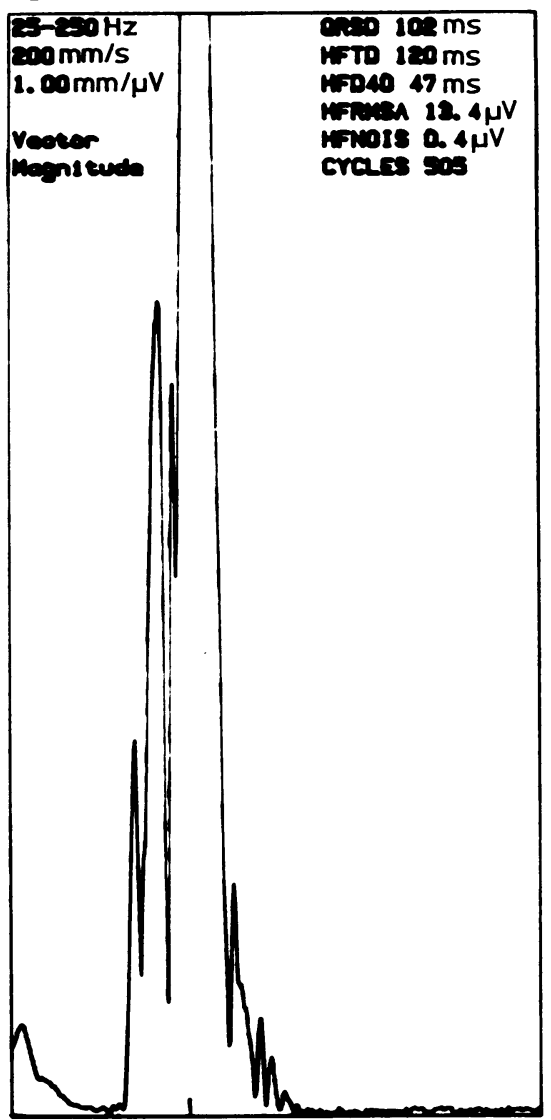

Figure An example of two high gain signal averaged electrocardiograms. (a) This recording is within normal limits and was recorded from a patient with an uncomplicated course. (b) This recording comes from a patient who died suddenly after myocardial infarction and it shows a prominent late potential. QRSD, $Q R S$ duration; HFTD, high frequency total $Q R S$ duration; HFD40, duration of high frequency low amplitude signals $(<40 \mu V) ; H F R M S A$, high frequency root mean square voltage of signals in the last 40 ms of the high frequency $Q R S ; H F N O I S$, high frequency noise level; cycles, number of averaged $Q R S$ complexes.

on admission (Killip class and Norris index) in predicting arrhythmic events. Clinical evidence of substantial infarction (that is Killip class $\geqslant$ II or a Norris index of $>9$ ) was specific for the prediction of arrhythmic events (specificity $91 \%$ and $95 \%$ respectively), but was insensitive (sensitivities $55 \%$ and $45 \%$ ). Thus the value of a combination of either a positive tape ( $\geqslant 10$ ventricular extrasystoles/hour) or late potentials with the clinical data was limited by low sensitivity (sensitivity $36 \%$ for tape with Killip $\geqslant$ II and $45 \%$ for late potentials with Killip $\geqslant$ II), though the positive predictive value of each test was improved by taking into account the Killip class (positive predictive accuracy $50 \%$ for tape in the presence of Killip class $\geqslant$ II and $63 \%$ for late potentials in the presence of Killip class $\geqslant$ II).

\section{Discussion}

The purpose of this study was to confirm that in the first week after myocardial infarction two bedside non-invasive techniques (signal averaged electro-

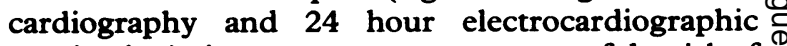
monitoring) give an accurate assessment of the risk of the occurrence of sudden death and sustained ven- 0 tricular tachycardia. Previous studies have establi- 0 shed the relation between prognosis after myocardial $\mathbb{\Omega}$ infarction and the results of 24 hour electrocar- $\mathbb{\nabla}$ 
Table 2 Prospective large scale studies of the value of signal averaged electrocardiography and ambulatory monitoring in the prediction of arrhythmic events after acute myocardial infarction

\begin{tabular}{|c|c|c|c|c|c|c|c|c|c|c|c|}
\hline \multirow[b]{2}{*}{ Authors } & \multirow[b]{2}{*}{ No } & \multirow{2}{*}{$\begin{array}{l}\text { Mean }(S D) \\
\text { time since } M I \\
(h)\end{array}$} & \multirow[b]{2}{*}{$S A E C G$} & \multirow[b]{2}{*}{ Filter } & \multicolumn{4}{|c|}{ Criteria for positive SAECG } & \multicolumn{3}{|c|}{ Prediction of $A E$} \\
\hline & & & & & fQRSD & $L P D 40$ & RMSV40 & Noise & Sens & Spec & $P P A$ \\
\hline $\begin{array}{l}\text { Kuchar et al } \\
\text { Gomes et al } \\
\text { Present study }\end{array}$ & $\begin{array}{l}200 \\
102 \\
159\end{array}$ & $\begin{array}{r}11(6) \\
10(6) \\
3(3)\end{array}$ & $\begin{array}{l}\text { ART } \\
\text { ART } \\
\text { ART }\end{array}$ & $\begin{array}{l}40 \mathrm{~Hz} \\
40 \mathrm{~Hz} \\
25 \mathrm{~Hz}\end{array}$ & $\begin{array}{l}>120 \\
>114 \\
\geqslant 120\end{array}$ & $\begin{array}{l}> \\
>38 \\
>40\end{array}$ & $\begin{array}{l}<20 \\
\leqslant 20 \\
\leqslant 25\end{array}$ & $\begin{array}{l}\text { n/s } \\
\text { n/s } \\
<1 \mu V\end{array}$ & $\begin{array}{r}65 \\
100 \\
73\end{array}$ & $\begin{array}{l}89 \\
45 \\
97\end{array}$ & $\begin{array}{l}32 \\
35 \\
62\end{array}$ \\
\hline
\end{tabular}

No, number of patients having both signal averaged ECG and 24 hour tape; SAECG, high gain, signal averaged electrocardiogram; sens, sensitivity; spec, specificity; PPA, positive predictive accuracy; $n / s$, not stated; $A E$, arrhythmic events; fQRSD, filtered $Q R S$ duration of $\geqslant 120 \mathrm{~ms} ; \mathrm{LPD} 40$, duration of the filtered QRS complex after voltage falls below $40 \mu \mathrm{V}$ of $\geqslant 40 \mathrm{~ms} ; \mathrm{RMSV40}$, root mean square voltage during the last $40 \mathrm{~ms}$ of the filtered QRS complex of $\leqslant 25 \mu \mathrm{V}$; ART, Arrhythmia Research Technology.

diographic monitoring ${ }^{9-11}$ and the high gain, signal averaged electrocardiogram. Although both tests provide prognostic information that is independent of clinical assessment and ejection fraction their clinical usefulness is limited by their low positive predictive accuracy.

Others have examined the relation between the results of signal averaged electrocardiogram and 24 hour electrocardiographic monitoring. The study of Kanovsky et al was not prospective nor did they evaluate consecutive series of patients with myocardial infarction. ${ }^{12}$ They compared two groups of patients referred for invasive investigation-a control group that did not have a history of ventricular tachycardia at a median of eight weeks after myocardial infarction and a group with documented ventricular tachycardia at a median of 46 weeks after infarction. No follow up data on the "control" group was available and so in some of them arrhythmic events could have developed subsequently. The presence of a late potential (fQRSD $>120 \mathrm{~ms}$ and/or RMSV40 $<25 \mu \mathrm{V}$ ), the presence on 24 hour monitoring of a peak rate for ventricular extrasystoles of $>100$ per hour, and the presence of an aneurysm on cineventriculography were independently associated with a history of ventricular tachycardia. There was little improvement in the prediction of arrhythmic events when the results of signal averaged electrocardiography were combined with either those of 24 hour monitoring or contrast ventriculography, but when all three were combined a sensitivity of $81 \%$, a specificity of $90 \%$, and a predictive accuracy of $85 \%$ were achieved.

More recently, Kuchar et al ${ }^{4}$ reported a study that was similar in design to our own. They too found an independent association between the results of signal averaged electrocardiography, 24 hour monitoring (Lown grade), and left ventricular function assessed by radionuclide angiography. The power of the combination of signal averaged electrocardiogram and 24 hour electrocardiographic monitoring in the prediction of arrhythmic events was: sensitivity $65 \%$, specificity $89 \%$, and positive predictive accuracy $32 \%$. A second series has been reported by Gomes et al..$^{5}$ Again the triad of ejection fraction, signal averaged electrocardiogram, and 24 hour electrocardiographic monitoring was assessed in relation to arrhythmic events during follow up, by the system used by Kuchar et al. Table 2 shows that the accuracy of prediction of arrhythmic events was more sensitive but less specific than that reported by Kuchar et al. A further increase in predictive accuracy, from $35 \%$ to $50 \%$, was achieved, without loss of sensitivity, by adding ejection fraction data.

In accord with the previous studies we found that the signal averaged electrocardiogram, while acceptably sensitive in predicting arrhythmic events during follow up after myocardial infarction $(91 \%)$, had a low positive predictive accuracy $(26 \%)$, which limits its clinical usefulness. In combination with the 24 hour tape, however, the predictive accuracy is increased considerably, with only moderate loss of sensitivity (table 2). Of the five patients who had positive results in both tests but have not yet had an arrhythmic event, three have had coronary artery bypass surgery which will have influenced the outcome. Longer follow up may increase the accuracy of this predictive combination even further.

It is not certain why the predictive accuracy of the combination of tape and signal averaged electrocardiogram was higher in our study than it was in those of Kuchar et al and Gomes et al. There were, however, several differences in the three studies. In our study the signal averaged electrocardiogram was performed earlier than in the other two studies, in most cases within the first week and in $44(28 \%)$ cases within the first day after infarction. It is often assumed that, in view of the evidence that there is variability in some of the electrophysiological properties of the myocardium soon after infarction, ${ }^{13}$ the signal averaged electrocardiogram will also be labile if recorded soon after infarction. This has not been our experience: there were no more changes between $<72$ hours and one month follow up than was reported for a $>1$ month and 6 month follow up, ${ }^{14}$ and comparable prognostic information was 
obtained from these early recordings. Many physicians discharge patients a week or even earlier after myocardial infarction and if information on the tendency to arrhythmia can be obtained before discharge it will be useful in management. Furthermore, some patients who die of early arrhythmia may be missed without early analysis. The population we studied may have differed in some respects from those in previous studies, none of which were from the United Kingdom. Our population consisted of a consecutive series of patients admitted with acute myocardial infarction and was representative of patients admitted to a general hospital with acute myocardial infarction.

Another important difference between the studies is the corner frequency chosen for high pass filtering of the signal averaged electrocardiogram. The equipment we used resembles that of Kuchar et $a l^{4}$ and Gomes et al,,$^{5}$ except that the high pass filter was fixed at $25 \mathrm{~Hz}$ rather than $40 \mathrm{~Hz}$. The optimal level for filtering is not known: the system of Breithardt et al $^{15}$ uses a high pass filter at $100 \mathrm{~Hz}$, that of Uther's group uses virtually no filtering at all. ${ }^{16}$ Gomes et $a l^{17}$ subsequently found that the $25 \mathrm{~Hz}$ filter had less sensitivity but more specificity than the $40 \mathrm{~Hz}$ filter in identifying patients with a history of ventricular tachycardia and those without. This is entirely consistent with our results (table 2).

The values used for the definition of the presence of late potentials is also different in the three studies (table 2). Our groups were selected before the start of the study and were based on Simson's comparison of patients with a history of myocardial infarction with or without documented ventricular tachycardia in which he used a comparable system with $25 \mathrm{~Hz}$ filtering. ${ }^{8}$ We also used the frequency of extrasystoles rather than Lown grade to quantify the arrhythmias on 24 hour electrocardiographic monitoring, as did Kuchar et $a l,{ }^{4}$ because the Lown system has some deficiencies, ${ }^{18}$ particularly the undue weight given to early extrasystoles (Lown grade 5 ).

We did not examine in detail the relation between left ventricular function and arrhythmic events. Although several studies have shown the importance of left ventricular ejection fraction as a prognostic determinant, accurate objective measurement of left ventricular function is not widely available. Most district hospitals do not have access to radionuclide ventriculography, and it is neither desirable nor possible to refer all patients with myocardial infarction for cineangiographic ventriculography. Access to 24 hour electrocardiographic monitoring, however, is more general, and has the great advantage that it can be performed by a technician. The signal averaged electrocardiograph we used is simple to use. At present it is little used, but if it were shown to be of clinical value it could be installed at a fraction of the cost of the equipment and expertise required for $c$. radionuclide angiography. We suggest that simple, $\overrightarrow{\vec{F}}$ rapid, cheap non-invasive tests should be used in the first instance to screen post-infarction patients, who then may proceed to more detailed evaluation if the screening tests are positive.

We did not include the results of exercise testing, which has an established place in risk stratification is after myocardial infarction, in this study. This test $\vec{\circ}$ would be expected to be of particular value in $\overrightarrow{\vec{H}}$ predicting ischaemic events after infarction and is $\dot{\omega}$ therefore complementary to the tests we have described, which are directed purely to the identification of arrhythmic risk. We used only arrhythmic events as end points in this study.

We have, however, examined the clinical state of $\infty$ the patients on admission, as reflected in the Killip o class and Norris index, to determine whether the predictive value of the signal averaged electro- $\bar{c}$ cardiogram and 24 hour monitoring was equalled or $\mathbb{D}$ even exceeded by simple clinical observation. $\mathbb{\Phi}$ Although the clinical state of the patient on admis- $\frac{3}{\sigma}$ sion did have some value in predicting outcome, the $\stackrel{\mathbb{}}{-}$ sensitivity and predictive value were less than either $\vec{\bullet}$ of the tests individually, and considerably less than $\infty_{\infty}^{\circ}$ those of the combination. Clinical variables are designed to be prognostic of in-hospital mortality, and those who died in the first seven days were excluded from our long term prognostic study.

As expected, the positive predictive accuracy of $\frac{\otimes}{\varnothing}$ both the tape and the signal averaged electrocardiogram was greater if there was also clinical $\stackrel{0}{\circ}$ evidence of substantial infarction, but the value of 3 these combinations in predicting arrhythmic events was limited by their lower sensitivity. Thus while the positive predictive accuracy of a positive tape $(\geqslant 10 \stackrel{\mathrm{\sigma}}{\mathrm{T}}$

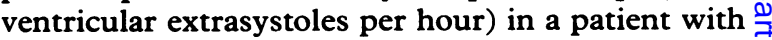
Killip class $\geqslant$ II was increased to $50 \%$, this finding $\frac{0}{5}$ was present in only four of 11 patients with arrhythmic events. With the combination of a positive tape $\delta$ and late potentials the sensitivity remained fairly $₹$ high (8/11 arrhythmic events predicted), and there $\frac{9}{7}$ was a substantial increase in positive predictive $D$ accuracy (8/13 with positive results had an event). Our results suggest that the tendency to arrhythmia N can be accurately assessed within the first week of myocardial infarction by a combination of the high $\tilde{O}$ gain, signal averaged electrocardiogram and 24 hour $N$ electrocardiographic monitoring. The value of antiarrhythmic treatment in this high risk group iso uncertain, but the identification of a group of patients with a very high risk of arrhythmic events will? increase the power of trials designed to test the value of antiarrhythmic treatment in patients after myocar-웅 dial infarction. 


\section{References}

1 El-Sherif N, Hope RR, Scherlag BJ, Lazzara R. Reentrant ventricular arrhythmias in the late myocardial infarction period. 2: Patterns of initiation and termination of re-entry. Circulation 1977;55:702-19.

2 Lown B. Sudden cardiac death: the major challenge confronting contemporary cardiology. Am J Cardiol 1979;43:313-28.

3 Simson MB, Untereker WJ, Spielman SR, et al. The relationship between late potentials on the body surface and directly recorded fragmented electrograms in patients with ventricular tachycardia. Am J Cardiol 1983;57:105-12.

4 Kuchar DL, Thorburn CW, Sammel NL. Prediction of serious arrhythmic events after myocardial infarction: signal averaged electrocardiogram, Holter monitoring and radionuclide ventriculography. $\mathrm{J} \mathrm{Am}$ Coll Cardiol 1987;9:531-8.

5 Gomes J, Winters SL, Stewart D, et al. A new noninvasive index to predict sustained ventricular tachycardia and sudden death in the first year after myocardial infarction: based on the signal averaged electrocardiogram, radionuclide ejection fraction and Holter monitoring. J Am Coll Cardiol 1987;10: 349-57.

6 Killip T, Kimball JT. Treatment of myocardial infarction in a coronary care unit. A two year experience with 250 patients. Am J Cardiol 1967;20:457-64.

7 Norris RM, Brandt PWT, Caughey DE, Lee AJ, Scott PJ. A new coronary prognostic index. Lancet 1969;i:274-8.

8 Simson MB. Use of signals in the terminal QRS complex to identify patients with ventricular tachycardia after myocardial infarction. Circulation 1981;64:235-42.

9 Davis HT, DeCamilla J, Bayer LW, Moss AJ. Survivorship patterns in the posthospital phase of myocardial infarction. Circulation 1979;60:1252-8.

10 Mukharii J, Rude RE, Poole K, et al. Risk factors for sudden death after acute myocardial infarction: two year follow up. Am J Cardiol 1984;54:31-6.

11 Bigger JT, Fleiss JL, Kleiger R, et al. The relationship among ventricular arrhythmias, left ventricular dysfunction and mortality in the 2 years after myocardial infarction. Circulation 1984;69:250-8.

12 Kanovsky MS, Falcone RA, Dresden CA, Josephson ME, Simson MB. Identification of patients with ventricular tachycardia after myocardial infarction: signal-averaged electrocardiogram, Holter monitoring and cardiac catheterisation. Circulation 1984;70:264-70.

13 Cobbe SM, Hoffman E, Ritzenhoff A, et al. Day to day variations in morphology and duration of fragmented ventricular potentials during the late post-myocardial infarction phase in conscious dogs. Eur Heart $J$ 1985;6:672-80.

14 Denniss AR, Ross DL, Richards DA, Uther JB. Changes in ventricular activation time on the signal averaged electrocardiogram in the first year after myocardial infarction. Am J Cardiol 1987;60:580-3.

15 Breithardt G, Schwarzmaier J, Borggrefe $M$, Haerten K, Seipel L. Prognostic significance of late ventricular potentials after acute myocardial infarction. Eur Heart J 1983;4:487-95.

16 Denniss AR, Richards DA, Cody DV, et al. Prognostic significance of ventricular tachycardia and fibrillation induced at programmed stimulation and delayed potentials detected on the signal averaged electrocardiograms of survivors of acute myocardial infarction. Circulation 1986;4:731-45.

17 Gomes JA, Winters SL, Stewart D, Targonski A, Barreca P. Optimal bandpass filters for the timedomain analysis of the signal averaged electrocardiogram. Am J Cardiol 1987;60:1290-8.

18 Bigger JT, Wenger TL, Heissenbuttel RH. Limitations of the Lown grading system for the study of human ventricular arrhythmias. Am Heart J 1977;93:727-9. 